\title{
Environmental Impacts of Solar Thermal Systems with Life Cycle Assessment
}

\author{
Alexis de Laborderie ${ }^{1 *}$, Clément Puech ${ }^{1}$, Nadine Adra ${ }^{1}$, Isabelle Blanc ${ }^{2}$, Didier Beloin-Saint- \\ Pierre $^{2}$, Pierryves Padey ${ }^{2}$, Jérôme Payet ${ }^{3}$, Marion Sie $^{3}$, Philippe Jacquin ${ }^{4}$ \\ ${ }^{1}$ Transénergie, Ecully, France \\ ${ }^{2}$ MINES ParisTech, Sophia Antipolis, France \\ ${ }^{3}$ Cycleco, Ambérieu, France \\ ${ }^{4}$ PHK Consultants, Ecully, France \\ *Corresponding author. Tel: +33 472860407, Fax: +33 472860400, E-mail: a.delaborderie@transenergie.eu
}

\begin{abstract}
Solar thermal systems are an ecological way of providing domestic hot water. They are experiencing a rapid growth since the beginning of the last decade. This study characterizes the environmental performances of such installations with a life-cycle approach. The methodology is based on the application of the international standards of Life Cycle Assessment. Two types of systems are presented. Firstly a temperate-climate system, with solar thermal collectors and a backup energy as heat sources. Secondly, a tropical system, with thermosiphonic solar thermal system and no backup energy. For temperate-climate systems, two alternatives are presented: the first one with gas backup energy, and the second one with electric backup energy. These two scenarios are compared to two conventional scenarios providing the same service, but without solar thermal systems. Life cycle inventories are based on manufacturer data combined with additional calculations and assumptions. The fabrication of the components for temperate-climate systems has a minor influence on overall impacts. The environmental impacts are mostly explained by the additional energy consumed and therefore depend on the type of energy backup that is used. The study shows that the energy pay-back time of solar systems is lower than 2 years considering gas or electric energy when compared to $100 \%$ gas or electric systems.
\end{abstract}

Keywords: Environmental impact, LCA, Solar thermal systems

\section{Introduction}

Solar thermal systems have encountered a high interest over the last ten years in many locations worldwide [1,2]. Indeed, it is a robust, efficient and simple technology to implement for individual households: solar thermal relies on well known process and materials. Its capacity in reducing energy load for domestic hot water (DHW) is significant in locations with high irradiation level.

Some studies have been carried out on thermosiphon solar water heaters in different countries [3-6] but none was focused on solar thermal systems with auxiliary energy source. This study is focused on this second type of installation since they often are preferred for NorthernEuropean countries (collector and storage with integrated backup).

The main purpose of the work is to characterize the environmental impacts of solar domestic hot water systems, or solar water heaters (SWH), integrating auxiliary heating (electric or gas heaters). Furthermore, this study also aims at identifying the most discriminating parameters to support implementation solutions. These systems' performances are analyzed as casestudies both for temperate climates (typically in France) and for tropical climates (typically in the Caribbean).

Life Cycle Assessment (LCA) methodology is used for this environmental evaluation. Among several LCA impact indicators, this study focuses on primary energy consumption, global warming potential, effect on ecosystem quality and human health issues. Greenhouse gas emissions (expressed in $\mathrm{CO}_{2}$ equivalent) and non-renewable energy consumption are considered here as key LCA outputs. 
Environmental performances of the different SWH with gas-backup, electrical-backup or no backup (for tropical zone's systems) are compared with standard hot water systems without any solar contribution.

\section{Methodology}

This Life Cycle Assessment (LCA) study was performed in compliance with the ISO standards 14040 and 14044 [7,8].

\subsection{Scope of the study}

This study has been carried out on individual solar thermal systems applied in the case of temperate and tropical climates. For temperate locations, four systems have been studied, namely two traditional systems without solar systems considering only electricity or gas heater, and two systems with solar system and integrated backup energy (electricity backup see Fig. 1 or gas backup). Due to the irregular solar irradiation all over the year, this kind of solar thermal system requires a backup system to reach the target temperature.

For tropical climates, one thermosiphonic solar system (without backup energy) has been analyzed (Fig. 2).

To study both temperate and tropical systems, two climatologically average located places have been determined, namely Lyon (continental France) for temperate climate and Le Lamentin (Martinique, overseas France) for tropical climate.

The solar systems configuration and backup energy uses are different according to the climatic conditions. Therefore, two different Functional Units have been defined:

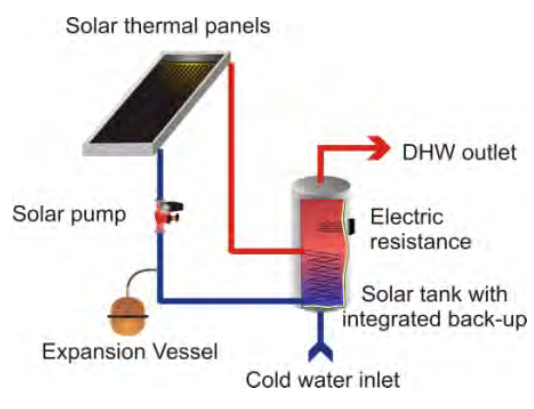

Fig. 1. Sketch-plan of temperate-type solar water heaters (electric backup)

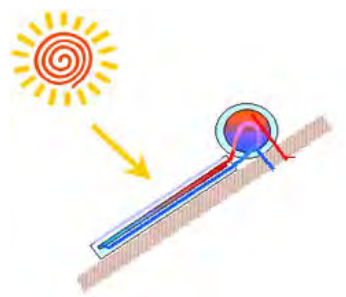

Fig. 2. Sketch-plan of tropical-type solar water heaters

The temperate climate Functional Unit: Production of DHW for a four-person household, (assessed to be 140 litres of $60^{\circ} \mathrm{C}$ ) in temperate climate and 20 years of life expectancy.

The tropical climate Functional Unit: Production of DHW for a four-person household, (assessed to be 200 litres of $50^{\circ} \mathrm{C}$ ) in tropical climate and 20 years of life expectancy.

Given that tropical-type SWH does not include backup energy, the target temperature $\left(50^{\circ} \mathrm{C}\right)$ is an indicator required to calculate solar energy but it does not represent the real outlet water temperature.

Corresponding irradiation levels and electricity mixes have been considered.

\subsection{Inventory}

\subsubsection{Inventory building strategy and sources}

Many hypotheses are necessary to evaluate the life cycle environmental impacts of DHW production. These hypothesis have been defined with the expertise of the consulting and 
engineering partner ${ }^{1}$ as well as technical data collected from public industrial actors. Thus, the different systems' component has been determined and sized. On the second hand, inventories for the electricity mix have been determined for the temperate-climate system.

For this study, the ecoinvent 2.0 LCI database [9] was used. Ecoinvent 2.0 contains international industrial life cycle inventory data on a various range of activities (energy supply, resource extraction, transport services,...). However, most of the SWH components are not defined exactly in the existing database. Thus, it has been necessary to modify or create new processes. When components' inventories were available in the database they were assessed in order to determine the validity of this inventory regarding the components' origin and main characteristics (materials used, manufacturing process and weight). When necessary, some inventories were modified by applying a weight or size ratio. Some inventories have also been completed by specific technical data collected within this project. When no inventory was available for a component, a new inventory has been built by the project team to estimate the required data.

As for the construction of the inventory, the composition of each component comes from different sources, which are described in Table 1.

Table 1. Data collection for infrastructures in scenarios

\begin{tabular}{|c|c|}
\hline Component & Sources \\
\hline Solar panel & Ecoinvent modified (to match with the surface defined for the scenarios) \\
\hline Water Pump & Ecoinvent modified (estimates, from the mass of material) \\
\hline Expansion Vessel & Ecoinvent (slightly oversized compared to usual design, but minor impact) \\
\hline Hot water tank & Ecoinvent modified (from a 2000 l tank) \\
\hline Solar regulation & Rough estimate (from the mass of the material, mostly electronics) \\
\hline Mounting support & Datasheets from manufacturers, completed by estimates when necessary \\
\hline Plumbing & Experience and estimates from the consulting and engineering partner \\
\hline Electrical backup & Ecoinvent (slightly oversized, but minor impact) \\
\hline Gas backup & Ecoinvent modified (to exclude the impacts related to domestic heating) \\
\hline
\end{tabular}

\subsubsection{System boundaries}

The system boundaries are described in Fig. 3. They include the solar panels manufacturing (panels, mounting systems), water tanks, internal heat exchanger, pipes, hydraulic components (pumps, valves, expansion vessel), regulation, cabling and solar fluid. In addition, they also include the use phase (backup energy consumption for temperate-climate SWH) and the recycling of components.

\footnotetext{
${ }^{1}$ Transénergie, http://www.transenergie.eu
}

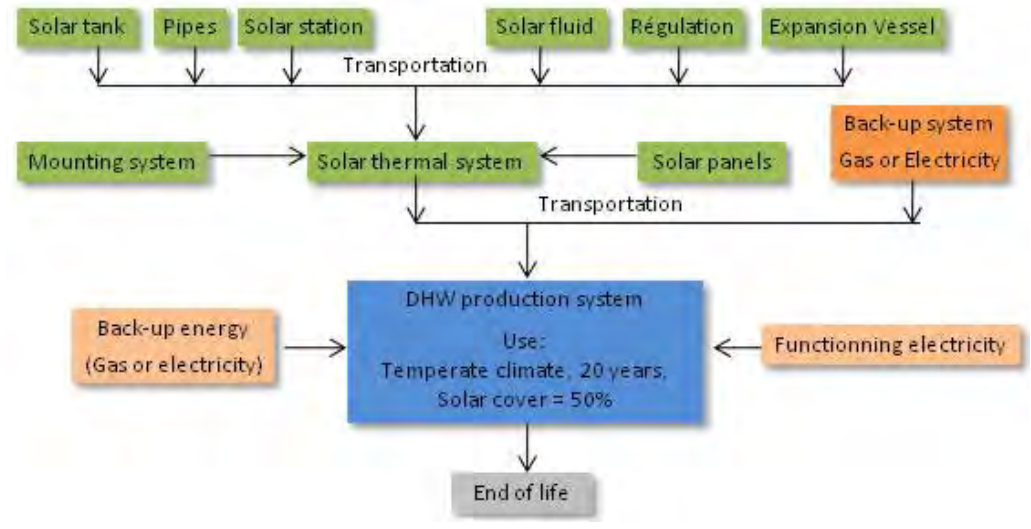

Fig. 3. Scheme of system boundaries 


\subsubsection{Scenarios}

Table 2 describes the four scenarios (scenarios 1-4) built for this study used for temperate climate systems. Scenario 5, standing as a reference for other scenarios results, comes from the ecoinvent 2.0 database.

Table 2. Scenarios for temperate climates

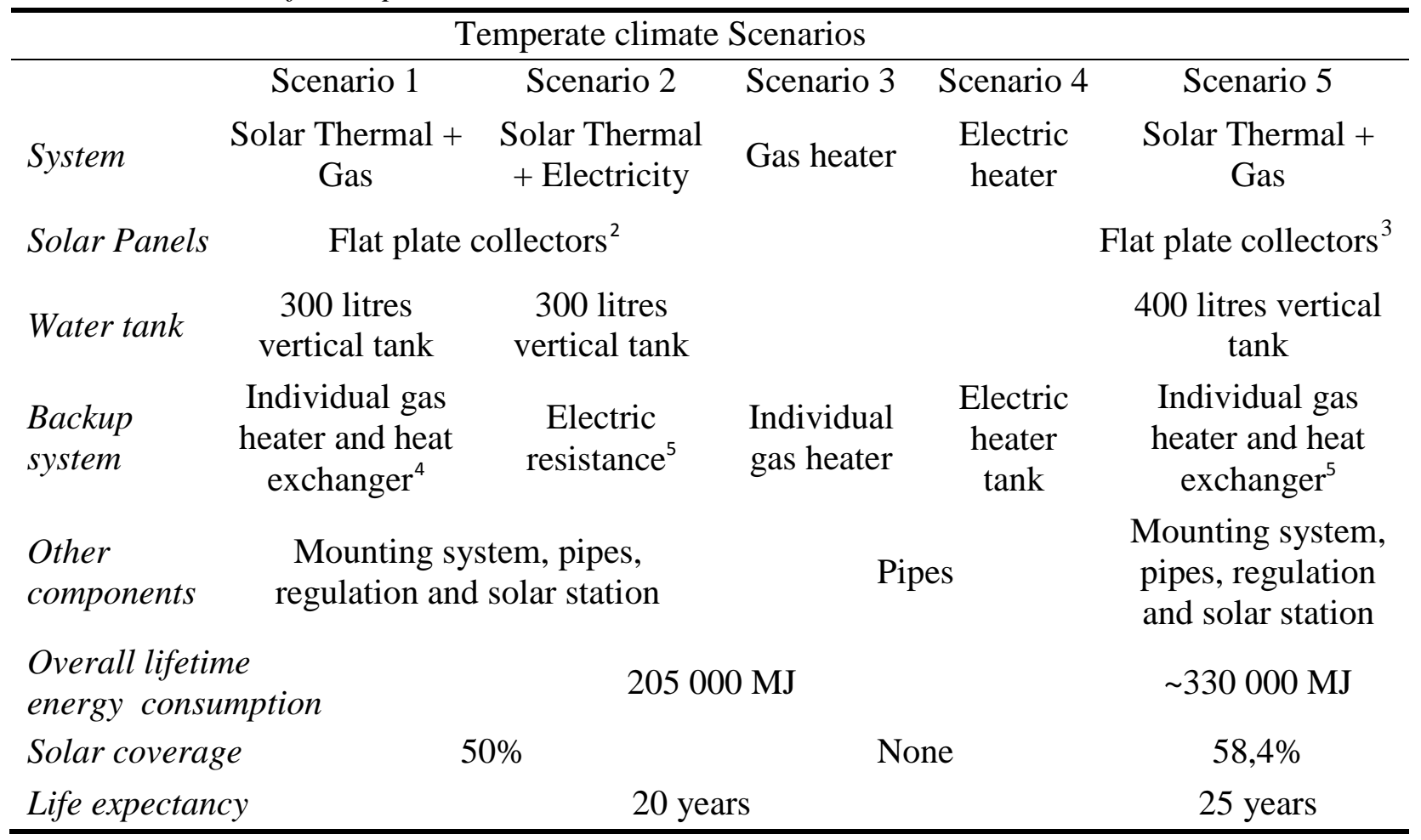

Table 3 describes the scenario built for this study for tropical SWH which is based on a thermosiphonic solar system. Flat plate collectors inventory is an average of the three main products that exists on the Caribbean market.
Table 3. Scenarios for tropical climate systems

\begin{tabular}{ll}
\hline \multicolumn{2}{l}{ Tropical climate Scenarios } \\
System & Thermosiphon \\
Solar Panels & Flat plate collectors ${ }^{5}$ \\
Solar tank & 200 l horizontal tank \\
Other components & Mounting system, pipes \\
$\begin{array}{l}\text { Overall lifetime energy } \\
\text { consumption }\end{array}$ & $147000 \mathrm{MJ}$ \\
Life expectancy & 20 years \\
\hline
\end{tabular}

Thermosiphon$$
\text { Elat plate collectors }
$$

Mounting system, pipes

$147000 \mathrm{MJ}$

20 years

\subsection{Payback time indicator}

Energy Payback Time (EBPT) has been calculated with the following definition:

$$
E P B T=\frac{E_{p}^{\text {fabrication }}+E_{p}^{\text {backup }}}{\text { avoided } E_{p}^{\text {production }}}
$$

\footnotetext{
${ }^{2}$ Collector Area $=4,4 \mathrm{~m}^{2}$ with solar panel coefficients : $\mathrm{B}=0,75 ; \mathrm{K}=4,5 \mathrm{~W} /\left(\mathrm{m}^{2} . \mathrm{K}\right)$

${ }^{3}$ Collector Area $=4 \mathrm{~m}^{2}$ with unknown solar panel coefficients

4 Integrated in the upper part of the tank

${ }^{5}$ Collector Area $=2 \mathrm{~m}^{2}$ with solar panel coefficients : $\mathrm{B}=0,75 ; \mathrm{K}=4,5 \mathrm{~W} /\left(\mathrm{m}^{2} . \mathrm{K}\right)$
} 
$E_{p}^{\text {fabrication }}$ : Non-renewable primary energy used for the fabrication of the installation.

$E_{p}^{\text {backup }}:$ Non-renewable primary energy used for the backup system.

avoided $E_{p}^{\text {production }}$ : Non-renewable primary energy avoided (thanks to the backup energy used, in case of electric backup, specific electricity mix of the country avoided where the SWH is installed.

In the case of electric backup or the comparison with the full electric system, this method of calculating EPBT gives results only valid for the country where the solar panels are installed.

\section{Results and analysis}

Results have been calculated according to the impact 2002+ (v2.04) [10] method available in SimaPro 7.1 PhD and the database ecoinvent 2.0.

\subsection{Temperate climate-type systems}

\subsubsection{Overall environmental impacts}

Scenarios are compared among all impact categories in figure 4. Figures 5 and 6 present the results for the most significant impact categories with the details of their origin.

It strikes that the necessary water auxiliary heating has a strong influence on the overall impact indicators. In the case of a SWH with electric backup (scenario 2), $\mathrm{CO}_{2}$ equivalent emissions are significantly cut down compared to a SWH with gas backup (scenario 1).

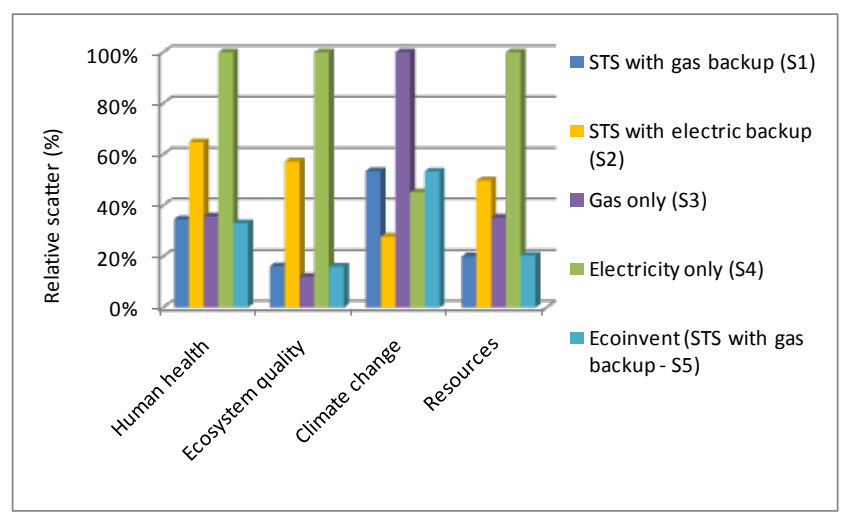

Fig. 4. Comparison of the temperate-climatetype scenarios on the complete lifetime

However, considering the other three impact categories, SWH with gas backup appears as the best impact reduction potential option compared to "traditional systems" (scenarios 3 and 4: respectively gas only or electricity only) as well as SWH with electric backup.

It is important here to point out that the electricity mix chosen here influences thoroughly the environmental performances of the ST installation, as well as the comparison with the electricity only scenario. Indeed, according to ecoinvent 2.0, the French electricity mix has particularly low carbon content: 103g/kWh. Thus, the energy backup's choice is critical according to the environmental impact reduction targeted.

\subsubsection{Distribution of environmental impacts}

The graphs below presents the climate change and non-renewable primary energy impacts. They show the distribution of the impacts of each scenario for the different main life cycle components.

In each of the five scenarios, transports (of materials to the manufacturing plant, as well as of the products to the installation location) play a minor role in non-renewable primary energy consumption. The electricity consumed for the operation of the SWH accounts for a smaller amount of non-renewable primary energy too. Backup energy consumptions stand by far 
(>80-90\%) for the most important part of for the climate change and non-renewable primary energy consumption impacts. Components of the solar thermal systems (solar thermal panels, pumps, solar tank and regulation system) finally make up for a lesser part of overall impacts, and once produced, consume very little electricity in the operating phase while providing $50 \%$ of DHW energetic demand.

In the case of electric backup, $\mathrm{CO}_{2}$ equivalent emissions are low because the electricity mix chosen is mainly based on nuclear energy (France) and has particularly low $\mathrm{CO}_{2}$ emissions. On the other hand, the French electricity mix has an important primary energy use (13.6 MJ of primary energy per $\mathrm{kWh}$, according to ecoinvent 2.0), which is why, in this precise configuration (scenario 2), electric backup stands for 91\% of non-renewable primary energy (see Fig. 5).

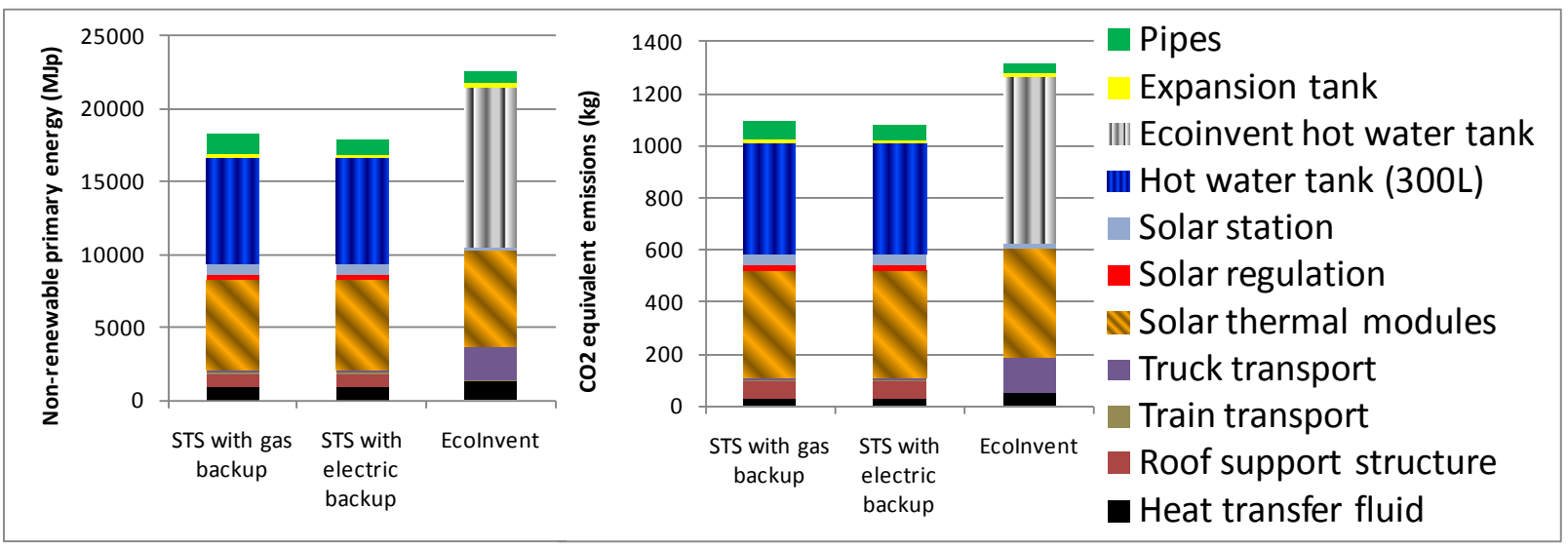

Fig. 5. Distribution of environmental impacts on climate change and non-renewable primary resources for the first four scenarios for temperate-climate-type SWH

Figure 6 shows the impacts of the fabrication of the solar thermal systems' components for the three scenarios with SWH. The results for those three scenarios show the same trend: solar thermal panels and the hot water tank are the major contributor to the environmental impacts of the two analyzed impact categories. Going further into details, it shows that the use of a large amount of steel stands for the most important part of the impacts of the hot water tank. As for solar thermal panels, it is aluminum (mainly for the frame) that causes most of the
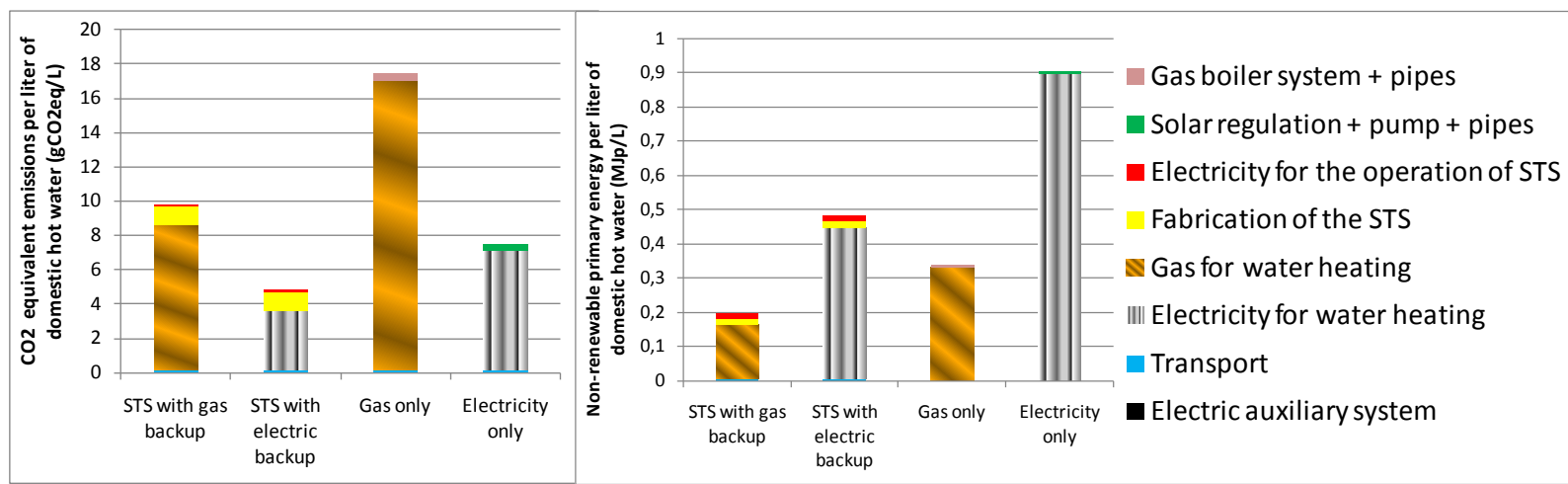

impacts. The major differences between the two SWH scenarios come from the fitting between the hot water tank and the boiler for the gas backup (fitting that is not necessary in the case of electric backup, which is integrated in the hot water tank).

Fig. 6. Detailed environmental impact potential of temperate-climate solar thermal system on climate change and non-renewable primary resources 


\subsubsection{Comparison with ecoinvent 2.0}

Scenario 5 (the ecoinvent scenario) shows significant different results compared to the first two scenarios. This is due to the water tank used which is $1 / 3$ larger in scenario 5 (400 l instead of $300 \mathrm{l}$ ). Besides, the transports hypotheses are much less favorable in scenario 5 compared to the first two. On the other hand, the supposed solar coverage ratio (SCR) is noticeably higher in the ecoinvent scenario while the solar thermal panels surface is lower: respectively $58.5 \%$ instead of $50 \%$ for the SCR, and $4 \mathrm{~m}^{2}$ instead of $4.4 \mathrm{~m}^{2}$. A further examination indicates that the main differences of results between the two sets of scenarios comes from hypotheses and choice of study parameters (lifetime, SCR, annual energy demand), and therefore shows the coherence between scenarios 1 (gas backup) and 2 (electrical backup) and the ecoinvent scenario (scenario 5).

\subsubsection{Energy payback time}

Energy payback time (cf. its definition in paragraph 1.3) has been studied in order to compare the energy required for the fabrication of SWH, to the energy avoided thanks to these systems while providing the same service (cf. functional unit). For the sake of clarity, only SWH with gas backup (scenario 1) has been compared to "traditional systems" (scenarios 3 and 4). Energy payback time is 1.5 years when comparing SWH with gas backup to gas only (scenario 1 to scenario 3), and less than 1 year when comparing SWH with gas backup to electricity only (scenario 4).

\subsection{Tropical-type scenario}

\subsubsection{Environmental impacts and distribution}

As detailed in Table 2, the solar thermal systems studied here as the tropical-type scenario shows specific differences with the systems used in temperate-climate conditions. Considering that the impact of gas or electricity consumption makes up the major part of overall impacts in the previous scenarios, the impacts of this scenario are significantly different from the previous in terms of distribution.

Fig. 7 shows the distribution of the impacts for each category. The water tank strikes as the major contributor to the impacts of the $\mathrm{SWH}$, between $31 \%$ and $60 \%$ of each impact.

The other significant contributions are made by the solar thermal panels (about 20\% of the impacts), the pipes (mostly because of the copper used), $23 \%$ and $31 \%$ respectively for human health and quality of ecosystems. The support structure accounts for $7 \%$ to $11 \%$ according to the impact category.

\subsubsection{Energy Payback Time}

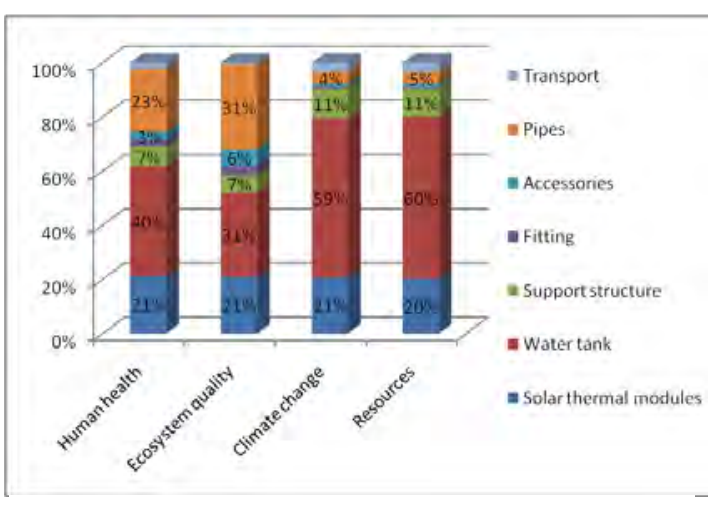

Fig. 7. Distribution of environmental impacts of the tropical-type SWH for each category of impact

Payback time of tropical SWH (with no auxiliary energy) ranges between 5 and 6 months.

\section{Conclusions, recommendations and perspectives}

This study clearly shows that solar thermal systems are a very interesting solution to reduce the environmental impacts of domestic hot water production.

The impact assessment results for temperate climate systems highlight the backup energy as the major factor on environmental impacts. However, this study does not end with a clear-cut 
environmental hierarchy among the different SWH systems: electricity or gas as a backup energy. This is mainly due to characteristics of the French electricity mix that has a low $\mathrm{CO}_{2}$ content but an important primary energy ratio.

For all SWH, regardless of backup energy, solar panels, water tank and pipes emerge as the key environmental components.

Therefore, considering those results, technical improvement related to the main impacting components can be realized to lower the environmental impacts of the solar thermal part of SWH.

This project has been followed by a LCA on larger solar thermal installations to determine their related environmental impacts and compare with domestic solar systems ${ }^{6}$.

\section{Acknowledgments}

ADEME (French Environment and Energy Management Agency) is co-financing this project which brings together different French specialists from the solar thermal industry and LCA fields.

\section{References}

[1] Eurobserv'er, Solar thermal Barometer, SYSTÈMES SOLAIRES - le journal des énergies renouvelables $N^{\circ} 191$, June 2009

[2] Solar Thermal Markets in Europe Trends and Market Statistics 2009, ESTIF, 2010

[3] Soteris Kalogirou, Thermal performance, economic and environmental life cycle analysis of thermosiphon solar water heaters, Solar Energy 83, 2009, pp. 39-48

[4] Fulvio Ardente, Life cycle assessment of a solar thermal collector: sensitivity analysis, energy and environmental balances, Renewable Energy 30, 2005, pp. 109-130

[5] Crawford, R. H., Net energy analysis of solar and conventional domestic hot water systems in Melbourne, Australia, Solar Energy 76, 2004, pp. 159-163

[6] Soteris Kalogirou, Environmental benefits of domestic solar energy systems, Energy Conversion and Management 45, 2004, pp. 3075-3092

[7] International Standard Organization. ISO 14040. Environmental management - Life Cycle Assessment - principles and framework. 2006

[8] International Standard Organization. ISO 14044. Environmental management - Life Cycle Assessment - requirements and guidelines. 2006.

[9] Swiss Center for Life Cycle Inventories. The life cycle inventory data version 2.0. http://www.ecoinvent.ch. 2008.

[10] O. Jolliet, M. Margni, R. Charles, S. Humbert, J. Payet, G. Rebitzer, R. Rosenbaum. Impact 2002+: A new life cycle impact assessment methodology, International Journal of Life Cycle Assessment. 2003. Volume: 8, Issue: 6, Pages: 324-330

\footnotetext{
${ }^{6}$ More information are available on http://www.esthace.eu
} 